\title{
Studying Reactivity Relationships of Copolymers N-naphthylacrylamide with (Acrylicacid and Methylacrylate)
}

\author{
Ameen Hadi Mohammed
}

\author{
Received 3/9/2018, Accepted 29/1/2019, Published 2/6/2019
}

This work is licensed under a Creative Commons Attribution 4.0 International License.

\begin{abstract}
:
The organation/monomer N-naphthylacrylamide (NAA) was prepared; subsequently the synthesized monomer was successfully copolymerized with acrylicacid (AA) and methylacrylate (MA) by free radical technique using dry benzene as solvent and benzoyl peroxide (BPO) as initiator. The overall conversion was kept low $(\leq 10 \% \mathrm{wt} / \mathrm{wt})$ for all studies copolymers samples. The synthesized monomer and copolymers were characterized using Fourier transform infrared spectroscopy (FT-IR), and their thermal properties were studied by DSC and TGA. The copolymers compositions were determined by elemental analysis. KelenTudes and Finmman-Ross graphical procedures were employed to determine the monomers reactivity ratios. The derived reactivity ratios $\left(\mathrm{r}_{1}, \mathrm{r}_{2}\right)$ are: $(0.048,0.687)$ for (NAA-co-AA) and $(0.066,0.346)$ for (NAA-coMA). Based on the average reactivity ratios, sequence distribution of monomers in the copolymers and the microstructure of copolymers were calculated by statistical method and found that these values are in agreement with the derived reactivity ratios.
\end{abstract}

Key words: Acrylic acid, Methyl acrylate, N-naphthylacrylamide, Reactivity relationships.

\section{Introduction:}

Monomers of $\mathrm{N}$-substituted acryl amide were prepared by a reaction of acryloyl chloride with different amines $(1,2)$. Many of these monomers were copolymerized and terpolymerized with other monomers $(3,4)$, several of these copolymers were used as drugs and pigments $(5,6)$. Copolymerization is a process of chain polymerization, whereby a combination of two monomers can be used to undertake copolymerization, which results in the formation of polymeric products with distinct compositions within the polymer chain that are called copolymers (7). The relative concentrations and reactivities of the two monomers dictate the proportions in which they are introduced into the copolymer. A combination of at least three monomers can enable the chain polymerization of different monomers to be conducted at the same time (8). These kinds of polymerizations are usually known as multicomponent copolymerizations, with a system of three monomers being termed terpolymerization. Valuable data have been derived from the implementation of chain copolymerization (9). Indeed, research on chain copolymerization has been the primary source of information about monomer reactivities underpinned by carbocations,

Department of Chemistry, College of Science of Women, University of Baghdad, Baghdad, Iraq

E-mail: ameenhadi80@yahoo.com free radicals and carbanions in chain polymerization. In particular, the response of reactivity to the chemical structure can be effectively investigated based on how monomers behave in reactions of copolymerization. Furthermore, copolymerization possesses technological significance as well. For example, it facilitates the development of a polymer product in accordance with a specific set of optimal attributes (10).

The properties of polymers can be most effectively modified with the help of the technique of copolymerisation (11). This technique is designed to manipulate the intra- and intermolecular forces that are exerted amongst similar and dissimilar polymer segments, engendering broad variation in properties like temperature of glass transition, melting point, solubility, permeability, dyeability, adhesion, elasticity and chemical reactivity. The basic explorations of structure property correlations and the variety of commercial and biological applications all attest to the fact that copolymerisation is highly useful (12). A copolymer composition equation relies greatly on reactivity ratios, which not only indicate the relative reactivity of pairs of monomers, but also outline the elements making up the copolymers. To understand how its utility has developed, it is first necessary to understand the copolymer composition itself. As 
emphasised above, the reactivity ratios are essential for copolymer composition and the manner in which it is distributed. The empirical data regarding copolymer composition and monomer feed mixtures must be mathematically processed before the monomer reactivity ratios can be determined. The reactivity of various comonomers can be calculated via a range of techniques. Furthermore, different analytical methods have been proposed to find out how much of a comonomer has been included in the copolymer (13).

New scientifically and commercially relevant materials can be obtained when two distinct monomers with various physical and or chemical attributes are incorporated in the same polymer molecule at different ratios. The monomer reactivity ratios of copolymerisation enable the determination of the relative reactivity of a monomer toward a specific polymer radical.

A copolymers composition is a critical factor in the assessment of its uses. Controlling the polymer property parameters, for example, molecular weight averages, sequence distribution, and copolymer composition, which is a specific significance in the copolymerization forms (14). To figure the rate of polymerization or polymer profitability and copolymer synthesis, monomer reactivity proportions must be known (15). Reactivity ratios are among the most essential parameters for the structure condition of the copolymer, as they can offer data, for example, the copolymer piece. Assurance of the monomer reactivity ratios with little interims requires delicate systematic methods (16).

The technique which is utilized frequently recently for evaluating monomer reactivity ratios is to perform low conversion copolymerization at different starting monomer feed compositions. In this way, the copolymer composition is resolved for every reaction. Conventional techniques for evaluating monomer reactivity ratios depend on, first, changing the momentary copolymer composition equation into a frame that is straight in the parameters $r_{1}$ and $r_{2}$ and after that assessing the monomer reactivity ratios by graphical plotting or by the direct minimum squares technique. Linearization of the copolymer composition condition will contort the blunder dispersions related with the information $(17,18,19)$.

The aims of this work are to synthesize a new monomer (NAA) then copolymerized with different monomers (AA and MA). This work also studied the reactivity relationships of the prepared copolymers further than their thermal properties.

\section{Material and Methods: \\ Materials}

The monomers, initiator, and solvents were obtained from Aldrich-oma chemical Co, (AA) and (MA) were freed from the inhibitor by shaking with $10 \% \mathrm{~W} / \mathrm{V}$ aqueous $\mathrm{NaOH}$. After washing with water, they were vacuum distilled immediately prior to the copolymerization experiment. Initiator (benzoyl peroxide) was purified by twice recrystallizations from chloroform and refrigerated prior to use.

\section{Preparation of NAA Monomer}

N-Naphthyl acryl amide (NAA) was prepared as a reported procedure (20) by the reaction of Naphthyl amine (14.3 g, 0.1 mole) and acryloyl chloride ( $9.5 \mathrm{~g}, 0.1 \mathrm{~mole}$ ) in $200 \mathrm{ml}$ dry benzene containing $(0.2 \mathrm{~g})$ of hydroquinone and $(2 \mathrm{ml})$ of triethylamine. With continuous stirring for 10 hours, the reaction mixture was maintained at $-15{ }^{\circ} \mathrm{C}$. Then, the precipitated, N-Naphthylacryloyl amide was filtered off. The crude product was fractionated under reduced pressure, after evaporation of benzene and acryloyl chloride. Red N-Naphthyl acrylamide was obtained then purified by washing many times with ethanol; the reaction of preparation (NAA) monomer is shown in Scheme 1.

\section{Copolymerization}

Copolymerization of (NAA) with (AA) and (MA) were carried out using $(10 \mathrm{ml})$ dry benzene as solvent and $\left(1 \times 10^{-3} \mathrm{~mol} \mathrm{dm}^{-3}\right)(\mathrm{BPO})$ as initiator. In quick fit test glass tubes, the prescribed amount of monomers, initiator and solvent were charged, and then put in water bath at $\left(80^{\circ} \mathrm{C}\right)$. As shown in Table 1 , the feed ratio was varied in a series of copolymerization of (NAA) with (AA) and (MA) (NAA-co-AA) and (NAA-co-MA) whilst the total molar composition of the monomer mixture was maintained at $\left(1 \mathrm{~mol} \mathrm{dm}^{-3}\right)$. Before starting the reaction, Nitrogen gas was bubbled through the mixture for 5 minutes in order to remove all oxygen. Low conversion $(<10 \%)$ of copolymers was obtained by controlling the time of copolymerization. Petroleum ether (b.p. $40-60^{\circ} \mathrm{C}$ ) was used to precipitate the obtained copolymers. All the copolymers were filtered off, dissolved again in benzene, and precipitated in petroleum ether prior to constant weight in vacuum at $40^{\circ} \mathrm{C}$. In order to determine the copolymer compositions, samples of the copolymer $(0.2 \mathrm{mg})$ were checked by elemental analysis. Scheme 1 shows the reaction of copolymerization (NAA) with (AA) and (MA) monomers. 

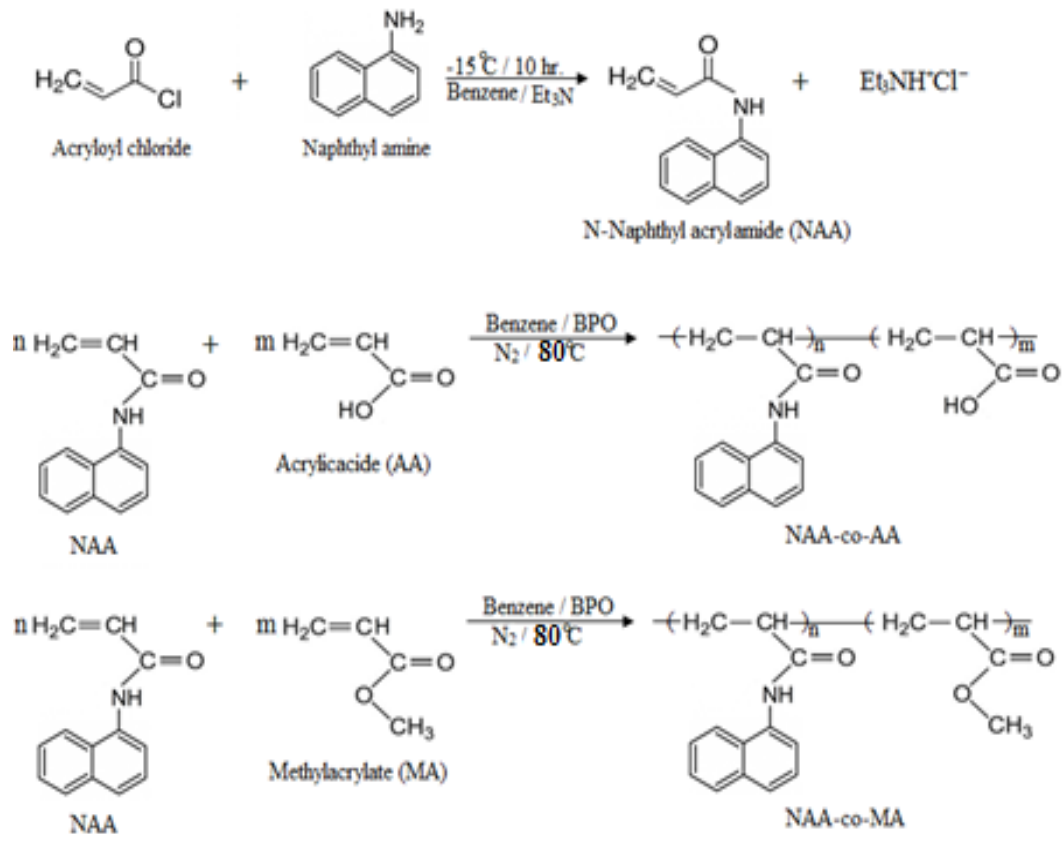

Scheme 1.Schematic illustration of the preparation (NAA), subsequently copolymerization with (AA) and (MA).

\section{Characterization}

Perken Elmer-1650 spectrometer was used to record FTIR spectra of the copolymers on $\mathrm{KBr}$ Pellets in the range $200-4000 \mathrm{~cm}^{-1}$. Intrinsic viscosity [y] was determined according to the Solomon Gotessman relationship (21) by using an Ostwald Viscometer with negligible kinetic energy correction. By following the variation of estimated nitrogen content arising from (NAA) comonomers units, copolymer compositions were determined by elemental analysis. DSC-Mettler calorimetric system was employed to determine the glass transition temperature ( $\mathrm{Tg}$ ) whilst Perkin Elmer in a nitrogen atmosphere at a heating rate of $10{ }^{\circ} \mathrm{C} / \mathrm{min}$ from 0 to $800{ }^{\circ} \mathrm{C}$ was used to study the thermal degradability of the copolymers.

\section{Results and Discussion:}

The structure of the prepared monomer and copolymers is confirmed by FT-IR as shown in Fig. 1. NAA structure was confirmed from the appearance of $3300 \mathrm{~cm}^{1}$ (amide N-H), $1590 \mathrm{~cm}^{-1}$ (alkene $\mathrm{C}=\mathrm{C}$ ) which merged with $1650 \mathrm{~cm}^{-1}$ (amide $\mathrm{C}=0$ ), $3150 \mathrm{~cm}^{-1}$ (alkene C-H), $1230 \mathrm{~cm}^{-1}$ (amide CN); NAA-co-AA: $3320 \mathrm{~cm}^{1}$ (amide N-H), $3000 \mathrm{~cm}^{1}$ (hydroxyl O-H), $1660 \mathrm{~cm}^{-1}$ (amide $\mathrm{C}=0$ ), $1720 \mathrm{~cm}^{-1}$ (carboxyl C=0), $1240 \mathrm{~cm}^{-1}$ (amide C-N), $2910 \mathrm{~cm}^{-1}$ (alkane $\mathrm{C}-\mathrm{H}$ ); NAA-co-MA: $3300 \mathrm{~cm}^{1}$ (amide N$\mathrm{H}), 1650 \mathrm{~cm}^{-1}$ (amide $\left.\mathrm{C}=0\right), 1750 \mathrm{~cm}^{-1}$ (ester $\mathrm{C}=0$ ), $1350 \mathrm{~cm}^{-1}$ (methyl C-H), $1220 \mathrm{~cm}^{-1}$ (amide C-N), $1010 \mathrm{~cm}^{-1}$ (ester C-O), $2900 \mathrm{~cm}^{-1}$ (alkane C-H).

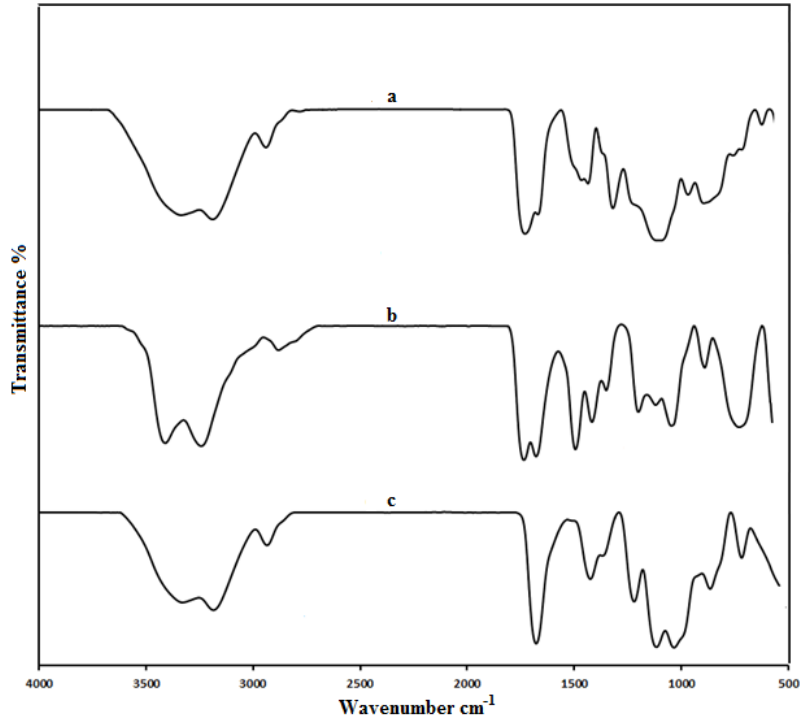

Figure 1. FT-IR of: a - NAA/AA copolymer, b NAA/MA copolymer, $c$ - NAA monomer.

\section{Copolymer Composition}

It is very useful to study the monomer reactivity in the copolymer system because the composition of the copolymer depends mainly on the monomer feed composition. In NAA/AA and NAA/MA copolymers, composition of the monomer in the copolymer was assessed by assurance $\mathrm{N} \%$ in the copolymers and this proportion indirectly gave the mole fraction of NAA in the copolymer. The monomer composition and the results of elemental analysis in addition to intrinsic viscosity values [П] for samples of five different compositions are listed in Table 1. The values of [ח] should be used in estimating qualitatively degree of polymerization (22). Figure 2 shows the plots of mole fraction of NAA in the 
copolymer $\left(\mathrm{F}_{1}\right) v s$. that of mole fraction of NAA in the feed $\left(f_{1}\right)$.

In the two systems, NAA forms alternates copolymer with AA and MA (Fig. 2a and b). Here, the presence of carbonyl and amide groups for each NAA monomer unit gave rise to a significant attraction of free electron in the double bond and generate a positive charge in the growing polymer chain and stabilization of the corresponding macroradical. Since NAA is electron rich, it forms the bond easily with electron deficient species, thus it is easily involved in polymerization.

When NAA is copolymerized with MA (Fig. 2a), a greater incorporation of NAA unit compared to NAA-AA copolymer has been observed. In this case, the double bond of MA appears to have slightly more positive charge due to the presence of carbonyl ester bond. The charge density generated on carbonyl carbon atom would favor a significant electron attraction in MA radicals, which creates a slightly more positive charge on the double bond. Due to electron deficiency in the double bond of MA, the electron-rich NAA is easily involved in copolymerization and hence, higher content of NAA is observed as compared to NAA-AA copolymer. A similar behavior was observed in our earlier case (23) wherein acrylamide was copolymerized with 3-(Trimethoxysilyl) Propyl Methacrylate, which contained similar carbonyl ester bond attached to the double bond.

Table 1.Feed and copolymer compositions, conversion, nitrogen analysis and intrinsic viscosity values

\begin{tabular}{cccccc}
\multicolumn{7}{c}{$[\boldsymbol{\eta}]$ of NAA/AA and NAA/MA copolymers. } \\
\hline Sample Code & $\mathbf{f}_{\mathbf{1}}$ (feed) & Conversion $\%$ & $\mathbf{N \%}$ & $\mathbf{F}_{\mathbf{1}}$ (copolymer) & {$[\boldsymbol{[}](\mathbf{d L} / \mathbf{g})$} \\
\hline NAA/AA-1 & 0.10 & 7.7 & 1.97 & 0.117 & 0.75 \\
NAA/AA-2 & 0.25 & 8.1 & 3.38 & 0.226 & 0.83 \\
NAA/AA-3 & 0.50 & 8.5 & 4.06 & 0.284 & 0.95 \\
NAA/AA-4 & 0.75 & 9.1 & 5.11 & 0.406 & 1.51 \\
NAA/AA-5 & 0.90 & 9.6 & 6.48 & 0.608 & 2.12 \\
NAA/MA-1 & 0.10 & 9.8 & 2.87 & 0.212 & 0.88 \\
NAA/MA-2 & 0.25 & 9.5 & 3.98 & 0.316 & 0.94 \\
NAA/MA-3 & 0.50 & 8.9 & 4.91 & 0.426 & 1.73 \\
NAA/MA-4 & 0.75 & 8.2 & 6.02 & 0.575 & 2.25 \\
NAA/MA-5 & 0.90 & 7.8 & 7.26 & 0.772 & 2.91 \\
\hline
\end{tabular}

(a) $\mathrm{f}_{1}$ is the mole fraction of monomer-1 (NAA) in the initial feed; $\mathrm{f}_{2}=1-\mathrm{f}_{1}$

(b) $\quad \mathrm{F}_{1}$ is the mole fraction of monomer-1 (NAA) in the copolymer; $\mathrm{F}_{2}=1-\mathrm{F}_{1}$

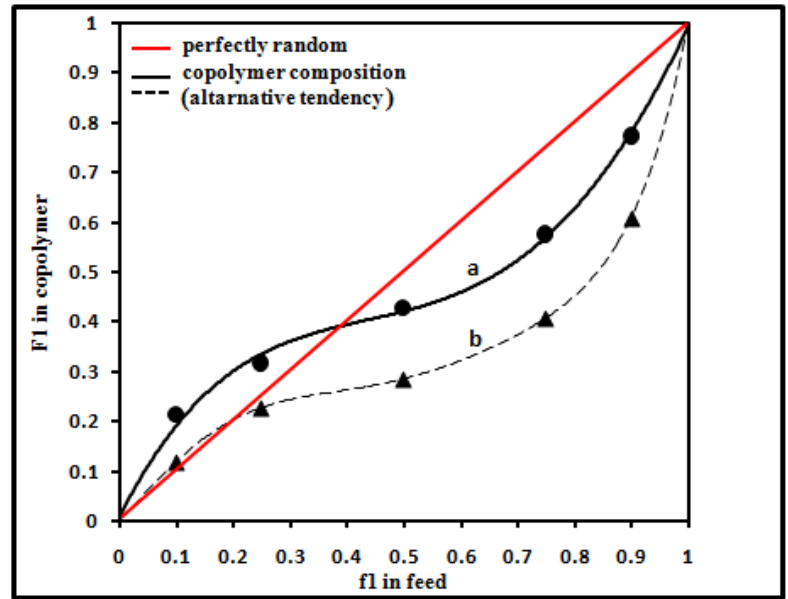

Figure 2. Variation of copolymer composition $F_{1}$ (AA) and $F_{1}$ (MA) with feed composition $f_{1}$ (AA) and $f_{1}$ (MA) for: a- NAA/AA, b-NAA/MA copolymers

\section{Reactivity Ratio}

The sort of copolymer framed can be best comprehended from the information of reactivity ratios of the copolymers. The most widely recognized scientific model of copolymerization depends on finding the connection between the composition of the monomer feed and the composition of copolymers in which the monomer reactivity ratios are the parameters to be resolved (24).In our work, two procedures have been used for the best fitting of $\left(r_{1} \& r_{2}\right)$ pair from a set of $\left[\mathrm{M}_{1}\right], \quad\left[\mathrm{M}_{2}\right], \mathrm{d}\left[\mathrm{M}_{1}\right]$ and $\mathrm{d}\left[\mathrm{M}_{2}\right]$ pair, using linearization methods representing by Kelen-Tudos and Fineman-Ross. The references $(25,26)$ of these methods should be consulted for more details about the mathematical processes. The values are showed in Fig. 3, 4, 5, 6, and represented in Table 2. 
Table 2.Kelen-Tudos and Fineman-Ross parameters of NAA/AA and NAA/MA copolymers.

\begin{tabular}{cccccc}
\hline Sample Code & $\mathbf{f}_{\mathbf{1}}$ (feed) & $\mathbf{G}$ & $\mathbf{X}$ & $\boldsymbol{\eta}$ & $\zeta$ \\
\hline NAA/AA-1 & 0.10 & -7.81 & 10.73 & -0.699 & 0.959 \\
NAA/AA-2 & 0.25 & -2.12 & 2.62 & -0.693 & 0.853 \\
NAA/AA-3 & 0.50 & -0.60 & 0.39 & -0.713 & 0.467 \\
NAA/AA-4 & 0.75 & -0.10 & 0.07 & -0.199 & 0.142 \\
NAA/AA-5 & 0.90 & 0.06 & 0.01 & 0.130 & 0.042 \\
NAA/MA-1 & 0.10 & -6.58 & 21.86 & -0.288 & 0.958 \\
NAA/MA-2 & 0.25 & -1.61 & 4.15 & -0.316 & 0.813 \\
NAA/MA-3 & 0.50 & -0.25 & 0.74 & -0.152 & 0.437 \\
NAA/MA-4 & 0.75 & 0.11 & 0.15 & 0.105 & 0.135 \\
NAA/MA-5 & 0.90 & 0.26 & 0.04 & 0.266 & 0.041 \\
\hline
\end{tabular}

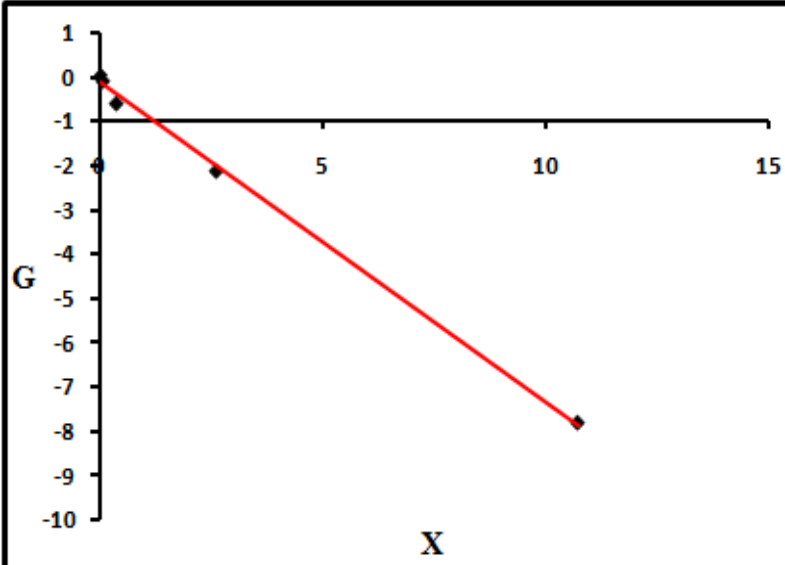

Figure 3.Fineman-Ross plot of NAA/AA copolymer.

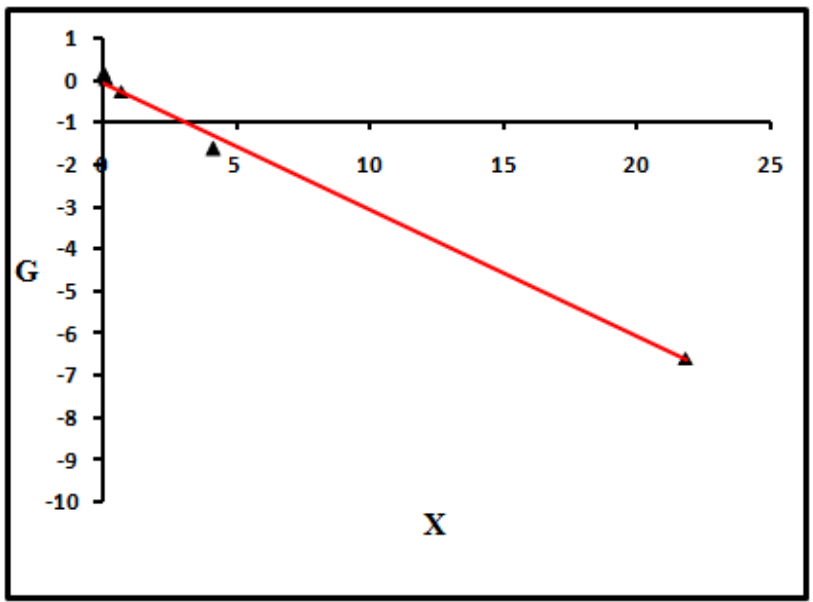

Figure 4.Fineman-Ross plot of NAA/MA copolymer.

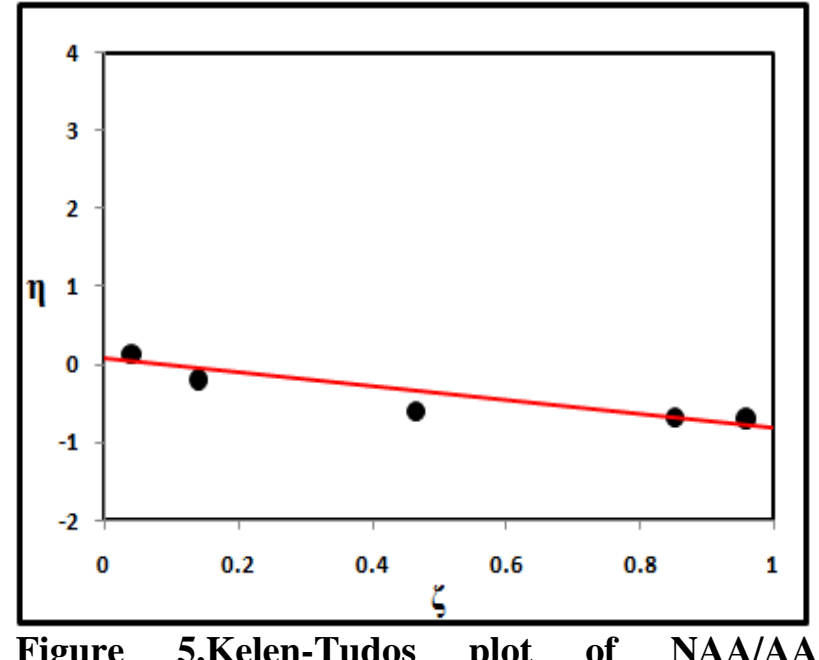

Figure 5.Kelen-Tudos plot of NAA/AA copolymer.

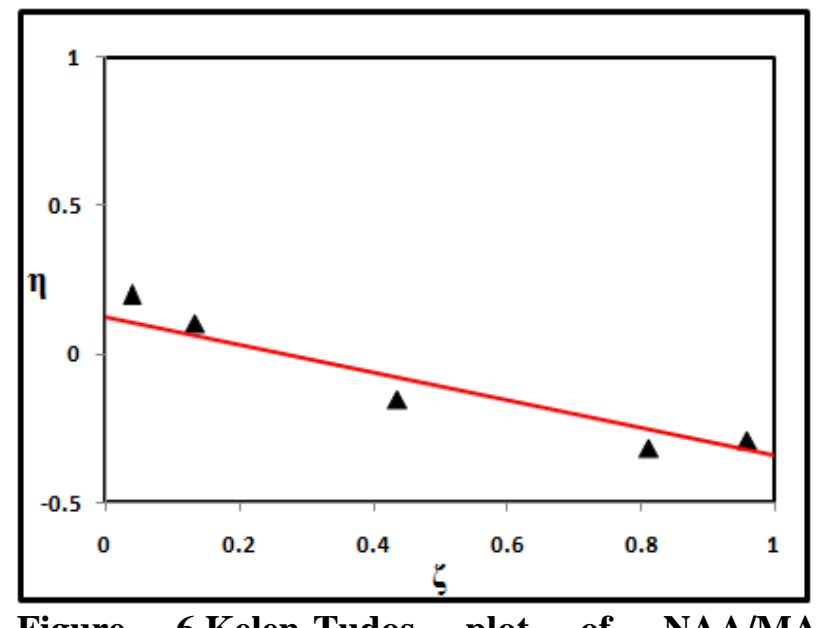

Figure 6.Kelen-Tudos plot of NAA/MA copolymer.

Table 3. Monomer reactivity ratios values for NAA-co-AA and NAA-co-MA

\begin{tabular}{llll}
\hline Copolymer & Procedure & $\mathbf{r}_{\mathbf{1}}$ & $\mathbf{r}_{\mathbf{2}}$ \\
\hline \multirow{3}{*}{ NAA/AA } & Kelen-Tudos & 0.051 & 0.679 \\
& Fineman-Ross & 0.046 & 0.695 \\
& Average values & 0.048 & 0.687 \\
\hline \multirow{2}{*}{ NAA/MA } & Kelen-Tudos & 0.071 & 0.342 \\
& Fineman-Ross & 0.062 & 0.351 \\
& Average values & 0.066 & 0.346 \\
\hline
\end{tabular}


Table 3 shows the values of reactivity ratios by different methods, the values $\left(r_{1}, r_{2}\right)$ from the different methods are very close. It is easy to observed that both (NAA/AA) and (NAA/MA) copolymers have the $r_{1} r_{2}$ values less than unity, demonstrating the alternation behavior of the monomers. The alternative behavior for the three monomers (NAA, AA and MA) could be explained in terms of increasing the stabilization of their radicals by the carbonyl groups resonance.

When the reactivity ratios of the two monomers are less than unity, the synthesized copolymer shows an alternating behavior. Each monomer prefers to react with other monomer more than itself (27).

The possibility of an azeotropic composition increases in case of $r_{1}, r_{2}$ are both $>1$ and $<1$. For both copolymers systems (NAA/AA and NAA/MA), this condition is fulfilled since $r_{1}$ and $r_{2}<1$. Fig. 2 (copolymer composition curve) proves this fact, in which a value of 0.41 for $\mathrm{f}_{1}$ (az.)in (NAA/MA) system and 0.23 in (NAA/AA) system. The azeotropic feed composition $\mathrm{f}_{1}(\mathrm{az}$.) can be expressed by the following equation:

$\mathrm{f}_{1}(\mathrm{az})=\left(1-\mathrm{r}_{2}\right) /\left(2-\mathrm{r}_{1}-\mathrm{r}_{2}\right)$

\section{Copolymer Microstructure}

The results of reactivity ratios were then utilized for microstructural figuring. The microstructure of the copolymers is required to be critical in deciding the arrangement properties which the copolymer shows (28). Igarashi's $(29,30)$ procedures are used to calculate the fraction of $\mathrm{M}_{1-}$ $\mathrm{M}_{1}, \mathrm{M}_{2}-\mathrm{M}_{2}$ and $\mathrm{M}_{1}-\mathrm{M}_{2}$ units in the copolymers, the data are listed in Table 4.

$$
\begin{aligned}
& S_{1-1}=m_{1}-\frac{2 m_{1} m_{2}}{1+\left[\left(2 m_{1}-1\right)^{2}+4 r_{1} r_{2} m_{1} m_{2}\right]^{1 / 2}} \\
& S_{2-2}=m_{2}-\frac{2 m_{1} m_{2}}{1+\left[\left(2 m_{1}-1\right)^{2}+4 r_{1} r_{2} m_{1} m_{2}\right]^{1 / 2}} \\
& S_{1-2}=\frac{4 m_{1} m_{2}}{1+\left[\left(2 m_{1}-1\right)^{2}+4 r_{1} r_{2} m_{1} m_{2}\right]^{1 / 2}}
\end{aligned}
$$

where: $\mathrm{m}_{1}$ (NAA) and $\mathrm{m}_{2}(\mathrm{AA}$ or $\mathrm{MA})-$ the mole fractions in the copolymer, $\mathrm{S}_{1^{-1}-}, \mathrm{S}_{2^{-2}}$, and $\mathrm{S}_{1^{-2}}$ - the mole fractions of 1-1, 2-2, and 1-2 sequences, respectively, $r_{1}$ and $r_{2}$ - the reactivity ratios.

The following equations were then used to calculate the probabilities of finding the sequence and the average length sequences of NAA, AA, and MA units $(31,32)$; the data are listed in Table 4.

$$
\begin{aligned}
& P 11=r_{1}[A] /\left(r_{1}[A]+[B]\right) \\
& P 22=r_{2}[B] /\left(r_{2}[B]+[A]\right) \\
& P 12=[B] /\left(r_{1}[A]+[B]\right) \\
& P 21=[A] /\left(r_{2}[B]+[A]\right) \\
& \mu_{1}=1 / P 12 \\
& \mu_{2}=1 / P 21
\end{aligned}
$$

where: A (NAA) and B (AA or MA) are the mole fractions in the feed. In these equations P11, P22, P12 and P21- the probability of a NAA or AA or MA unit to be followed by NAA or AA or MA unit.

Table 4.Statistical data of NAA/AA and NAA/MA copolymer.

\begin{tabular}{lllllllllll}
\hline code & $\begin{array}{c}\text { Sample } \\
(\mathrm{mol} \%)\end{array}$ & \multicolumn{2}{c}{$\begin{array}{c}\text { Blockness } \\
(\mathrm{mol} \%)\end{array}$} & Alternation & \multicolumn{2}{c}{ Sequence probability } & \multicolumn{3}{c}{ Sequence length } \\
& \multicolumn{2}{c}{$\mathrm{M}_{1}-\mathrm{M}_{1} \mathrm{M}_{2}-\mathrm{M}_{2}$} & $\mathrm{M}_{1}-\mathrm{M}_{2}$ & $\mathrm{P}_{11}$ & $\mathrm{P}_{22}$ & $\mathrm{P}_{12}$ & $\mathrm{P}_{21}$ & $\mu_{1}$ & $\mu_{2}$ & \\
\hline NAA/AA-1 & 3.63 & 63.09 & 33.28 & 0.005 & 0.860 & 0.994 & 0.139 & 1.005 & 7.194 \\
NAA/AA-2 & 5.41 & 45.40 & 49.19 & 0.015 & 0.673 & 0.984 & 0.326 & 1.016 & 3.067 \\
NAA/AA-3 & 8.33 & 29.43 & 62.24 & 0.045 & 0.406 & 0.954 & 0.593 & 1.048 & 1.686 \\
NAA/AA-4 & 11.53 & 13.39 & 75.08 & 0.125 & 0.185 & 0.874 & 0.814 & 1.144 & 1.228 \\
NAA/AA-5 & 16.47 & 7.42 & 76.42 & 0.301 & 0.070 & 0.698 & 0.929 & 1.432 & 1.076 \\
NAA/MA-1 & 10.71 & 30.04 & 59.25 & 0.006 & 0.753 & 0.993 & 0.246 & 1.007 & 4.065 \\
NAA/MA-2 & 15.57 & 20.32 & 64.11 & 0.019 & 0.504 & 0.980 & 0.495 & 1.020 & 2.022 \\
NAA/MA-3 & 24.33 & 9.45 & 66.22 & 0.056 & 0.253 & 0.943 & 0.746 & 1.061 & 1.342 \\
NAA/MA-4 & 28.24 & 3.59 & 68.17 & 0.152 & 0.101 & 0.847 & 0.898 & 1.180 & 1.113 \\
NAA/MA-5 & 29.28 & 1.64 & 69.08 & 0.350 & 0.036 & 0.649 & 0.963 & 1.540 & 1.038 \\
\hline
\end{tabular}

For both copolymers systems (NAA/AA and NAA/MA), $\left[\mathrm{M}_{1}\right]-\left[\mathrm{M}_{2}\right], \mathrm{P} 12$ and P21 increase as $\mathrm{AA}$ and MA increases. At the same time, these values are higher than $\left[\mathrm{M}_{1}\right]-\left[\mathrm{M}_{1}\right]$ and $\left[\mathrm{M}_{2}\right]-\left[\mathrm{M}_{2}\right]$, $\mathrm{P} 11$ and P22, respectively. From these results, AA in (NAA/AA) copolymer and MA in (NAA/MA) copolymer have a tendency to react with other monomer (NAA) rather than themselves in the growing chain to form alternation and block copolymers and these results are in agreement with the values of $r_{\mathrm{AA}}(0.68)$ and $\mathrm{r}_{\mathrm{MA}}(0.34)<1$.
For the system of NAA/AA copolymers, the mean sequence length of NAA, $\mu_{1}$, varied from 1.005 to 1.432 . For these copolymer compositions, values of $\mu_{2}$ were 7.194 and 1.076 respectively, similarly for the system NAA/MA, the $\mu_{1}$ varied from 1.540 to 1.007 , and for those copolymer compositions, values of $\mu_{2}$ were 4.065 and 1.038.

\section{Thermal Properties}

For NAA/AA-1 copolymer, $\mathrm{T}_{\mathrm{g}}$ value observed around $112{ }^{\circ} \mathrm{C}$ whereas NAA/MA-1 
copolymer showed the $\mathrm{T}_{\mathrm{g}}$ around $51{ }^{\circ} \mathrm{C}$. It is found that by increasing the amount of NAA content in the copolymers result in increased $\mathrm{T}_{\mathrm{g}}$, this may be due to the presence of rigid amide group in the backbone in NAA side chain. TGA results are presented in Fig. 7. The NAA/AA copolymer is more stable than the copolymer of NAA/MA with $10 \%$ weight loss at about $400{ }^{\circ} \mathrm{C}$ of NAA/AA-1 which is higher than $360{ }^{\circ} \mathrm{C}$ of NAA/MA-1. This result could be attributed to the presence of methyl group in the backbone in MA side chain which significantly lowers the $\mathrm{T}_{\mathrm{g}}$ value and the thermal stability of NAA/MA copolymer. Values of $\mathrm{T}_{\mathrm{g}}$ and data of TGA are given in Table 5.

Table 5.Thermal data of NAA/AA and NAA/MA copolymers.

\begin{tabular}{ccccc}
\hline Samples & $\mathbf{T}_{\mathbf{g}}\left({ }^{\circ} \mathbf{C}\right)$ & $\mathbf{T}_{\mathbf{1 0} \%}\left({ }^{\circ} \mathbf{C}\right)$ & $\mathbf{T}_{\mathbf{5 0} \%}\left({ }^{\circ} \mathbf{C}\right)$ & $\begin{array}{c}\text { Residual at } \\
\mathbf{8 0 0}{ }^{\circ} \mathbf{C} \\
(\mathbf{w t} \%)\end{array}$ \\
\hline NAA/AA-1 & 112 & 400 & 460 & 16 \\
NAA/MA-1 & 51 & 360 & 455 & 6 \\
\hline
\end{tabular}

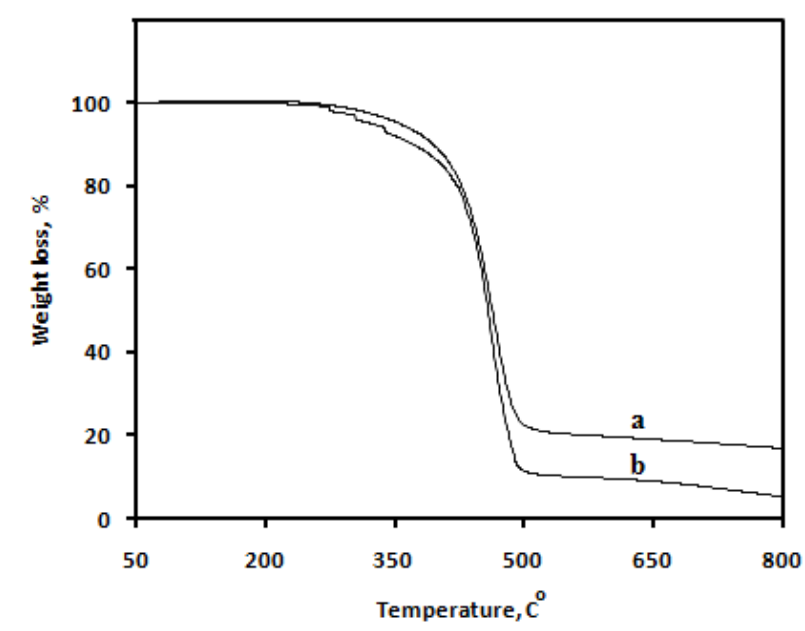

Figure 7. TGA thermogram of: (a) NAA-co-AA, (b) NAA-co-MA.

\section{Conclusions:}

The monomer NAA, NAA-co-AA and NAAco-MA were successfully synthesized. The structure of synthesized monomer and copolymers was confirmed by FT-IR technique. Elemental analysis test was employed to determine the copolymer compositions. Then, the results of $\mathrm{N} \%$ were used to calculate the reactivity ratios by different methods: Kelen-Tudosand Fineman-Rossmethods and a good agreement was observed between the two procedures. Both copolymers tend to be alternative $\left(r_{1}=0.048, r_{2}=0.34\right)$ and $\left(r_{1}=0.066, r_{2}=0.68\right)$ respectively. The results of sequence distribution of monomers and microstructure show a good agreement with the obtained reactivity ratios. DSC and TGA analysis were used to study the thermal properties of the copolymers.

\section{Conflicts of Interest: None.}

\section{References:}

1. Yuan Q, Sigman MS. Palladium-Catalyzed Enantioselective Relay Heck Arylation of Enelactams: Accessing $\alpha, \beta$-Unsaturated $\delta$-Lactams. J. Am. Chem. Soc. 2018; 140 (21):6527-6530.

2. Mahindaratne MP, Quiñones BA, Recio III A, Rodriguez EA, Lakner FJ, Negrete GR. A fullytelescoped, aqueous, auxiliary-mediated asymmetric transformation. ARKIVOC. 2005; 6:321-328.

3. Minami E, Tsukahara N, inventors; Adeka Corp, assignee. Copolymer and aqueous coating composition using same. United States patent application US. 2017; 15:518-555.

4. Crisante F, Taresco V, Donelli G, Vuotto C, Martinelli A, D'Ilario L, et.al.. Antioxidant hydroxytyrosol-based polyacrylate with antimicrobial and antiadhesive activity versus Staphylococcus epidermidis. IAMIDPH. 2015; 33:25-36.

5. Umeda S, Nakade H, Kakuchi T. Preparation of superabsorbent hydrogels from poly (aspartic acid) by chemical crosslinking. Polym. Bull. 2011; 67(7):1285-1292.

6. Palkowitz MD, Tan B, Hu H, Roth K, Bauer RA. Synthesis of diverse $\mathrm{N}$-acryloylazetidines and evaluation of their enhanced thiol reactivities. Org. Lett. 2017; 19(9):2270-3.

7. Mohammed AH, Al-Issa MA. Copolymerization of Acrylamide with Acrylic acid. Baghdad Science Journal. 2012; 9(2):285-8.

8. Gavrilov AA, Chertovich AV. Copolymerization of Partly Incompatible Monomers: An Insight from Computer Simulations. Macromolecules. 2017; 50(12):4677-85.

9. Ambade AV. Controlled radical polymerization. InMetal-Catalyzed Polymerization. 3th ed. USA: CRC Press; 2017. 161-177.

10. Erol I, Sen O, Dedelioglu A, Cifci C. Synthesis and characterization of novel fluorine-containing methacrylate copolymers: Reactivity ratios, thermal properties, and antimicrobial activity. J. Appl. Polym. Sci. 2009; 114(6):3351-9.

11. Beckingham BS, Sanoja GE, Lynd NA. Simple and Accurate Determination of Reactivity Ratios Using a Nonterminal Model of Chain Copolymerization. Macromolecules. 2015; 48(19):6922-30.

12. Mohammed AH, Ahmad MB, Ibrahim NA, Zainuddin N. Effect of crosslinking concentration on properties of 3-(trimethoxysilyl) propyl methacrylate/N-vinyl pyrrolidone gels. CHEM CENT J. 2018; 12(1):15-23.

13. Riahinezhad M, Kazemi N, McManus N, Penlidis A. Effect of ionic strength on the reactivity ratios of acrylamide/acrylic acid (sodium acrylate) copolymerization. J. Appl. Polym. Sci. 2014; 131(20):40949-55. 
14. El-Newehy MH, Al-Deyab SS, Al-Hazmi AM. Reactivity ratios for organotin copolymer systems. Molecules. 2010; 15(4):2749-58.

15. Habibi A, Vasheghani-Farahani E, Semsarzadeh MA, Sadaghiani K. Monomer reactivity ratios for lauryl methacrylate-isobutyl methacrylate in bulk free radical copolymerization. Polym Int. 2003; 52(9):1434-43.

16. Mohammed AH, Ahmad MB, Ibrahim NA, Zainuddin N. Synthesis and properties of vinylpyrrolidone/(trimethoxysilyl) propyl methacrylate gels containing different amounts of crosslinking agent. Polimery. 2018; 63(9):577-585.

17. Zubov A, Naeem O, Hauger SO, Bouaswaig A, Gjertsen F, SingstadP,et.al.. Bringing the On-Line Control and Optimization of Semibatch Emulsion Copolymerization to the Pilot Plant. MACROMOL REACT ENG. 2017; 11(4):14-29.

18. Manski CF, Tamer E. Inference on regressions with interval data on a regressor or outcome. Econometrica. 2002; 70(2):519-46.

19. Lanzalaco S, Armelin E. Poly (nisopropylacrylamide) and copolymers: A review on recent progresses in biomedical applications. Gels. 2017; 3(4):36-44.

20. Thirumoolan D, Basha KA, Kanai T, Safiullah SM, Vetrivel K, WasiKA,et.al.. Synthesis, characterization and reactivity ratios of poly $\mathrm{N}$-(p-bromophenyl)-2methacrylamide-Co-N-vinyl-2-pyrrolidone. SAUDI CHEM SOC. 2016; 20(2):195-200.

21. Mohammed AH. Polymerization of Acrylamide in Water. journal of the college of basic education. 2011; 16(68):19-28.

22. Nachman M, Kwiatkowski K. The effect of thermal annealing on the abrasion resistance of a segmented block copolymer urethane elastomers. Wear. 2013; 306(1-2):113-118.

23. Mohammed AH, Ahmad MB, Ibrahim NA, Zainuddin N. Synthesis and monomer reactivity ratios of acrylamide with 3-(trimethoxysilyl) propyl methacrylate and tris (methoxyethoxy) vinylsilane copolymers. Polimery. 2016; 61(11-12):758-65.
24. Acikses A, Taskan G, Barim G. A Study on Copolymer Systems of Styrene with Diethanolamine Side Group and Methyl Methacrylate. J Chem. 2018; 2018:1-12.

25. Kelen T, Tüdöus F, Turcsányi B, Kennedy JP. Analysis of the linear methods for determining copolymerization reactivity ratios. IV. A comprehensive and critical reexamination of carbocationic copolymerization data. J PolymSci A Polym Chem. 1977; 15(12):3047-74.

26. Fineman M, Ross SD. Linear method for determining monomer reactivity ratios in copolymerization. J. Polym. Sci. A. 1950; 5(2):259-62.

27. Anastasaki A, Nikolaou V, Nurumbetov G, Wilson P, Kempe K, Quinn JF,et.al.. Cu (0)-mediated living radical polymerization: a versatile tool for materials synthesis. Chem Rev. 2015; 116(3):835-77.

28. Craciun G, Ighigeanu D, Manaila E, Stelescu MD. Synthesis and characterization of poly (acrylamideco-acrylic acid) flocculant obtained by electron beam irradiation. Mater. Res. 2015; 18(5):984-93.

29. Igarashi S. Representation of composition and blockiness of the copolymer by a triangular coordinate system. J PolymSci B. 1963; 1(7):359-63.

30. Vijaykumar S, Prasannkumar S, Sherigara BS, Shelke NB, Aminabhavi TM, Reddy BS. Copolymerization of N-vinyl pyrrolidone with functionalized vinyl monomers: Synthesis, characterization and reactivity relationships. MACROMOL RES. 2009; 17(12):1003-9.

31. Parambil AM, Puttaiahgowda YM, Shankarappa P. Copolymerization of N-Vinyl pyrrolidone with methyl methacrylate by Ti (III)-DMG redox initiator. TURK J CHEM. 2012; 36(3):397-409.

32. Mohammed AH, Bin Ahmad M, Shameli K. Copolymerization of tris (methoxyethoxy) vinyl silane with $\mathrm{N}$-vinyl pyrrolidone: synthesis, characterization, and reactivity relationships. INT J POLYM SCI. 2015; 2015:1-8

\section{حساب نسب الفعالية للبوليمر المشترك اكريلويل نفثايل امايل مع حامض الاكريلك والمثيل اكريلات}

$$
\text { أمين هادي محمد }
$$

$$
\text { قسم الكيمياء، كلية العلوم للبنات، جامعة بغداد، بغداد، العراق }
$$

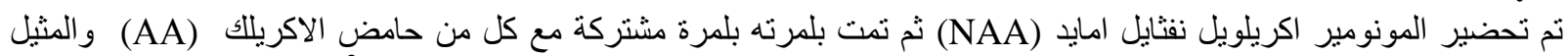

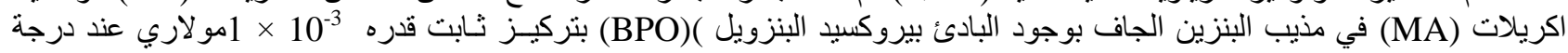

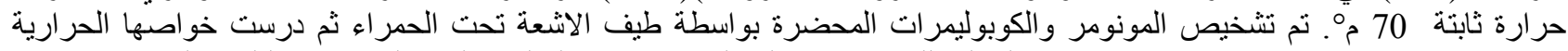

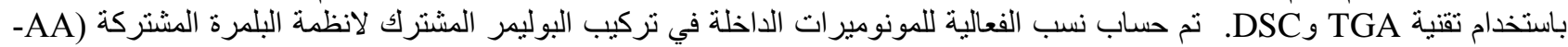

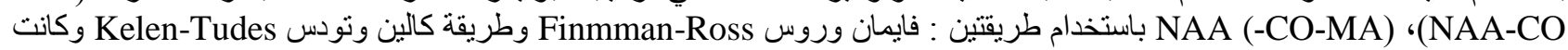

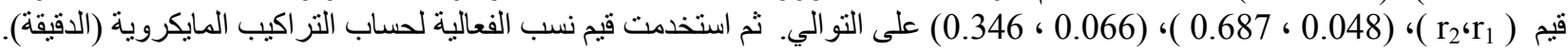
الكلمات المفتاحية: حامض الاكريلك، المثيل اكريلات، اكريلويل نفتايل امايد، نسب الفعالية
} 